\title{
A Recommended Program for Overcoming Learning Plateau with the Non-Preferred Arm and its Effects on the Three-Point Shot for Junior Basketball Players
}

\author{
Fatema Ahmed Hassan Basiouny ${ }^{1}$ \\ ${ }^{1}$ Assistant Professor, Department of Team and Racquet Sports, Faculty of Physical Education, Tanta University, Egypt
}

\begin{abstract}
:
The current research aims to identify the effects of an educational program on breaching the learning plateau for learning the three-point-shot for junior basketball players. The researcher used the experimental (one-group) design with pre- and post-measurements of the preferred and non-preferred arms. The researcher purposefully chose (15) junior basketball players (14-16 years) from Tanta Sports Club who were registered for the 2014-2015 season. Another (10) players from Saigar Sports Club were chosen as a pilot sample. Results indicated that there are statistically significant differences on $p \leq 0.05$ with effect size between (5.55) and (7.24) between the pre-and post-measurements of the technical test for the preferred arm in favor of the post-measurements. There are statistically significant differences on $p \leq 0.05$ with effect size between (4.12) and (5.88) between the pre-and post-measurements of the technical test for the non-preferred arm in favor of the post-measurements. There are statistically significant differences on $p \leq 0.05$ with effect size between (0.96) and (2.10) between the post-measurements of the technical test for the preferred and non-preferred arms in favor of the preferred arm. The recommended program for breaching the learning plateau had positive effects on the performance level of the three-point shot with the preferred arm.
\end{abstract}

Keywords: three-point shot-motor learning - learning plateau

\section{Introduction}

Chooting is of major importance in basketball and can

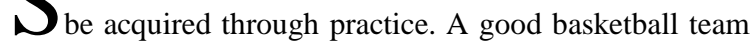
needs players with the ability to accomplish the final part of a successful attack by shooting as the match can be won or lost through the core of points. Training is one of the major conditions for learning motor skills. To learn a skill, the athlete needs to train and exert sufficient effort to control moves so that these moves become easy, accurate and fast in addition to performing such moves under all changing situations (Fawzy 2013).

Learning plateau is vital problem that faces coaches during applied training. It is a stage when no significant change in the athlete's performance is apparent although the athlete still trains but results are null. This phenomenon continues for a period of time according to its reasons. It is the result of various factors including the method of training, traditional exercises, lack of incentives and encouragement, ignoring modern methods of training, the low level of motivation and desire in addition to individual differences (Abd El-Fattah 2012).

Training junior athletes is more complicated than training adult athletes as working with juniors need solid-based knowledge about their characteristics, aptitudes, abilities, trends and attributes. Knowing this enables us to start and to direct the junior athlete towards the highest possible level in addition to breach the learning plateau through various modern methods of training and to make decisions about changing the training method according to clear bases to reach elite performance levels (Abd El-Khalek 2005).

As the game becomes faster, shooting becomes more important. Concerning shooting places and the scores related to them, the three-point shot makes it more difficult to predict the results of most basketball matches. In addition, basketball depends on shooting in the first place as all points are scored through shooting (ladder shot, jump (two-point) shot, three-point shot or free throw). It is noticeable that the three-point shot is very 
important as the team with most successful number of shots wins the match. This is consistent with Arias et al (2012), Garzin et al (2011), Pojskic et al (2011) and Arias et al (2011) who indicated the importance of shooting in identifying match results.

The researcher noticed that winning the match depends on the accuracy percentage of scoring free throws and threepoint shots. There are several teams who lost their games not due to their bad plays but due to their failure in shooting. Also, the researcher noticed the decrease of three-point shot skill in junior basketball players in addition to a learning plateau where the technical performance of this skill remains invariable although players are punctual in their training. This indicates that the training method does not match the desired performance requirements and does not lead to further progress. This makes it hard for junior players to pass this stage although shooting depends on individual skills. Ibrahim (2002) indicated that individual learning is closely related to cognitive functions and functional links inside the "task activation" areas as its activity increased during perception of the task. In addition, this stage is very critical and affects the performance level of athletes seriously. Although learning plateau may be a general phenomenon for some individuals, it has various reasons. The learning method may be incorrect or even the individual may acquire negative habits that hinder progress. Also, the quick and unsuitable increase in the learning situation progression may lead to it. In addition, some psychological factors like failure, fatigue or lack of self-confidence may lead to learning plateau. Learning methods and audio-visual aids may help avoiding this phenomenon. Furthermore, learning plateau may result from insufficient physical preparation or the lack of physical and psychological qualities necessary for individual learning.

Authors like Fawzy (2013), Abd El-Fattah (2012), Abd ElKhalek (2005), Ibrahim (2002), Yamashita et al (2015), Schiffer (2013) and Jasem (2008) agreed that for any motor skill, the learning curve can never sustain an infinite increase with continuous training due to the limits of the learning process which lead the learner to stay still on a certain level or even record a slight decrease. This makes the learning plateau looks like a flat or slightly inclined line on the learning curve. And in case of the final plateau, one or more of the motivational, material of physiological aspects used in the training process are responsible.
It is noteworthy to indicate that learning plateau is very common among beginners as they concentrate on specific exercises for a specific sports activity and sacrifice general development in a very early stage (Kurz 2001).

But it is also noteworthy that repeating the same exercises regularly helps generates a typical dynamic image in the nervous system. One reason for learning plateau is the extensive performance of certain exercises. These exercises not only lead to boredom but also to fatigue and stress. In addition, performance indicators are sustained on a specific level and this limits progress to higher levels (Tabachink 1992).

Therefore, coaches face two contradicted things. Athletes should perform with max speed to develop the skill while this speed may lead them to the learning plateau. The typical training theory indicated that there are two ways to avoid this problem. These are to change and vary training exercises and to train with training aids and learning plateau can be breached through changing methods of training and using the other part of the body (nonpreferred arm). (Schiffer 2001, Jasem 2008)

Through review of literature, the researcher did not find any Arabic of foreign studies that dealt with the learning plateau in basketball or the three-point shot. Through observing participants during the preparation stage, the researcher decided to improve the causes that form the framework of the educational program and its units as they are the base for overcoming the learning plateau. This is because players do not use training aids or varying exercises. This is specifically correct for countries with low economic standards or those who do not use training aids in improving motor learning.

This led the researcher to design a program for breaching learning plateau of the three-point shot skill depending on repetition, correcting mistakes and increasing accuracy.

The current research aims to identify the effects of an educational program on breaching the learning plateau for learning the three-point-shot for junior basketball players through varying exercises and training with the nonpreferred arm. The researcher hypothesized that there are statistically significant differences between the pre- and post-measurements of the three-point shot with the preferred arm in favor of the post-measurements, there are statistically significant differences between the pre- and post-measurements of the three-point shot with the nonpreferred arm in favor of the post-measurements and there are statistically significant differences between the post- 
measurements of the three-point shot with the preferred and non-preferred arms.

\section{Materials and Methods}

\section{Approach:}

The researcher used the experimental (one-group) design with pre- and post-measurements of the preferred and nonpreferred arms.

\section{Participants:}

The researcher purposefully chose (15) junior basketball players (14-16 years) from Tanta Sports Club who were registered for the 2014-2015 season. Those participants represent the club in official competitions and the researcher noticed that they suffer from their steady level of performance for the three-point shot during competition and training Another (10) players from Saigar Sports Club were chosen as a pilot sample. Table (1) shows normalization of data for participants.

Table (1) indicated that squewness and flatness values were between $( \pm 3)$. This indicates that physical aspect data is free of radical distributions.

Table (1)

Descriptive data for participants $(n=15)$

\begin{tabular}{|c|c|c|c|c|c|c|c|}
\hline \multicolumn{2}{|r|}{ Variables } & Measurements & Mean & Median & SD & Flatness & Squewness \\
\hline \multicolumn{8}{|c|}{ Growth factors } \\
\hline \multicolumn{2}{|r|}{ Age } & Year / month & 15.60 & 16.00 & 0.63 & 1.26 & $1.41-$ \\
\hline \multicolumn{2}{|r|}{ Height } & $\mathrm{Cm}$ & 170.53 & 170.00 & 7.03 & $0.90-$ & $0.38-$ \\
\hline \multicolumn{2}{|r|}{ Weight } & $\mathrm{Kg}$ & 62.13 & 60.00 & 7.59 & $0.63-$ & 0.08 \\
\hline \multicolumn{2}{|c|}{ Training period } & Year / month & 5.20 & 5.00 & 0.72 & $0.80-$ & $0.40-$ \\
\hline \multicolumn{8}{|c|}{ Physical tests } \\
\hline \multicolumn{2}{|c|}{ Vertical jump } & $\mathrm{Cm}$ & 55.00 & 54.00 & 5.03 & -0.52 & 0.59 \\
\hline \multicolumn{2}{|r|}{ Wide jump } & M & 1.87 & 1.85 & 0.10 & -1.00 & 0.51 \\
\hline \multicolumn{2}{|c|}{ Preferred arm } & M & 5.45 & 5.40 & 0.10 & -0.62 & 0.06 \\
\hline \multicolumn{2}{|c|}{ Non-preferred arm } & M & 3.95 & 3.75 & 0.44 & -1.70 & 0.37 \\
\hline \multicolumn{8}{|c|}{ Technical tests } \\
\hline \multirow{5}{*}{$\begin{array}{l}\vec{z} \\
\overrightarrow{00} \\
\vec{\alpha}\end{array}$} & 180 right & Degree & 1.47 & 1.00 & 0.52 & -2.31 & 0.15 \\
\hline & 45 right & Degree & 1.20 & 1.00 & 0.41 & 0.90 & 1.67 \\
\hline & Middle & Degree & 1.33 & 1.00 & 0.49 & -1.62 & 0.79 \\
\hline & 45 lift & Degree & 1.13 & 1.00 & 0.35 & 4.35 & 2.40 \\
\hline & 180 lift & Degree & 0.67 & 1.00 & 0.62 & -0.40 & 0.31 \\
\hline \multirow{5}{*}{$\leftrightarrows$} & 180 right & Degree & 0.40 & 0.00 & 0.51 & -2.09 & 0.46 \\
\hline & 45 right & Degree & 0.53 & 1.00 & 0.52 & -2.31 & -0.15 \\
\hline & Middle & Degree & 0.67 & 1.00 & 0.62 & -0.40 & 0.31 \\
\hline & 45 lift & Degree & 0.67 & 1.00 & 0.62 & -0.40 & 0.31 \\
\hline & $180 \mathrm{lift}$ & Degree & 0.40 & 0.00 & 0.63 & 1.26 & 1.41 \\
\hline
\end{tabular}

Table (1) indicated that squewness and flatness values were between $( \pm 3)$. This indicates that physical aspect data is free of radical distributions.

\section{Data collection tools:}

- The researcher used the following physical tests: vertical jump - wide jump - medicine ball throw with preferred arm - medicine ball throw with non-preferred arm to assure that physical aspect data is free of radical distributions. 
- The researcher used the following shooting tests: 180 degrees right -45 degrees right -90 degrees (middle) - 45 degrees left - 180 degrees left. Each player performs five shots for each point from outside the $6.75 \mathrm{~m}$ arc. Players move from one point to the next anti-clockwise. For each correct trial one point is scored.

The educational program for breaching learning plateau:

This program aims to breach the learning plateau of the three-point shot for junior basketball players during the preparation stage through:

- Initiating the program according to the requirements of breaking the players' adaptation to shooting performance using (25) technical exercises in situational/competitive mode for shooting from all possible angles (180 degrees right - 45 degrees right - 90 degrees [middle] - 45 degrees left - 180 degrees left). These exercises aim to improve shooting accuracy and speed with the non-preferred arm.

- Gradual increase in repetitions for the non-preferred arm compared to the preferred arm

- Progression from slow to fast duration of performance for the preferred and non-preferred arms

- Using the following training aids:

* Dummies and basketballs with various weights

* A training aid designed as a net surrounding the shooting board to help players correct the player's performance (ball arc and trajectory - shooting distance - ball pushing force

and velocity - kinesthetic perception - ball release and landing angles) and mistakes of shooting especially for the player's body shape and arm position

- The learning plateau program's units are separate from regular training of players in their club but under supervision of their coach

- The training program lasts for (12) weeks (2 units per week) and each unit includes (90) munities distributed as follows:

* Warm-up (10 min) for physical and physiological preparation of the body and getting ready for the unit's activities

* Main part (70 min) includes various and progressive exercises for improving the three-point shot

* Cool down (10 min) includes relaxation exercises to recover the body normal status

- Pre-measurements were taken before applying the program while post-measurements were taken immediately after the program

\section{Statistical treatments:}

Mean - median - SD - squewness - correlation coefficient $-(\mathrm{t})$ value - Cohen's effect size.

\section{Results}

Table (2)

Difference Significance and Effect Size between the Pre- and Post-measurements for the Preferred Arm on Technical Tests $(n=15)$

\begin{tabular}{|c|c|c|c|c|c|c|c|c|c|c|}
\hline \multirow{2}{*}{ Technical tests } & \multicolumn{2}{|c|}{ Pre- } & \multicolumn{2}{|c|}{ Post- } & \multirow{2}{*}{ Means difference } & Standard error & T & D2 & Effect size & Significance \\
\cline { 2 - 9 } & Mean & SD \pm & Mean & SD \pm & & & & & & \\
\hline 180 right & 1.47 & 0.52 & 4.4 & 0.63 & 2.93 & 0.23 & 12.86 & 0.92 & 7.24 & High \\
\hline 45 right & 1.2 & 0.41 & 4.47 & 0.52 & 3.27 & 0.15 & 21.31 & 0.97 & 7.03 & High \\
\hline Middle & 1.33 & 0.49 & 4.6 & 0.51 & 3.27 & 0.18 & 17.98 & 0.96 & 6.47 & High \\
\hline 45 lift & 1.13 & 0.35 & 4.27 & 0.7 & 3.13 & 0.19 & 16.33 & 0.95 & 5.55 & High \\
\hline 180 lift & 0.67 & 0.62 & 4.6 & 0.51 & 3.93 & 0.25 & 15.85 & 0.94 & 6.62 & High \\
\hline
\end{tabular}

(T) Table value on $\mathrm{P} \leq 0.05=1.76$

Effect Size: Low $=0.2-$ Moderate $=0.5-$ High $=0.8$

Table (2) indicated statistically significant differences on $\mathrm{P} \leq 0.05$ and a high effect size according to Cohen's equation between the pre- and post-measurements of the preferred arm on all technical tests as (t) calculated values were from (12.86) to $(21.31)$ which were higher than its table value (1.76) while the effect size ranged from (5.55) to (7.24) in favor of post-measurements. 
Table (3)

Difference Significance and Effect Size between the Pre- and Post-measurements for the Non-preferred Arm on Technical Tests $(\mathrm{n}=15)$

\begin{tabular}{|c|c|c|c|c|c|c|c|c|c|c|}
\hline \multirow{2}{*}{ Technical tests } & \multicolumn{2}{|c|}{ Pre- } & \multicolumn{2}{|c|}{ Post- } & \multirow{2}{*}{ Means difference } & Standard error & T & D2 & Effect size & Significance \\
\cline { 2 - 12 } & Mean & SD \pm & Mean & SD \pm & & & & & & \\
\hline 180 right & 0.4 & 0.51 & 3.6 & 0.51 & 3.2 & 0.22 & 14.38 & 0.93 & 5.88 & High \\
\hline 45 right & 0.53 & 0.52 & 3.47 & 0.52 & 2.93 & 0.21 & 14.22 & 0.93 & 4.69 & High \\
\hline Middle & 0.67 & 0.62 & 3.6 & 0.51 & 2.93 & 0.23 & 12.86 & 0.92 & 4.12 & High \\
\hline 45 lift & 0.67 & 0.62 & 3.6 & 0.51 & 2.93 & 0.21 & 14.22 & 0.93 & 5.26 & High \\
\hline 180 lift & 0.4 & 0.63 & 3.53 & 0.52 & 3.13 & 0.26 & 12.25 & 0.91 & 5.57 & High \\
\hline
\end{tabular}

(T) Table value on $\mathrm{P} \leq 0.05=1.76$

Effect Size: Low $=0.2-$ Moderate $=0.5-$ High $=0.8$

Table (3) indicated statistically significant differences on $\mathrm{P} \leq 0.05$ and a high effect size according to Cohen's equation between the pre- and post-measurements of the non-preferred arm on all technical tests as $(\mathrm{t})$ calculated values were from (12.25) to (14.38) which were higher than its table value (1.76) while the effect size ranged from (4.12) to (5.88) in favor of post-measurements.

Table (4)

Difference Significance and Effect Size between the Post-measurements for the Preferred and Non-preferred Arm on Technical Tests $(n=15)$

\begin{tabular}{|c|c|c|c|c|c|c|c|c|c|}
\hline \multirow[b]{2}{*}{ Technical tests } & \multicolumn{2}{|c|}{ Preferred } & \multicolumn{2}{|c|}{ Non-preferred } & \multirow[b]{2}{*}{ Means difference } & \multirow[b]{2}{*}{ Standard error } & \multirow[b]{2}{*}{$\mathrm{T}$} & \multirow[b]{2}{*}{$\mathrm{D} 2$} & \multirow[b]{2}{*}{ Effect size } \\
\hline & Mean & $\mathrm{SD} \pm$ & Mean & $\mathrm{SD} \pm$ & & & & & \\
\hline 180 right & 4.40 & 0.63 & 3.60 & 0.51 & 0.80 & 3.64 & 0.42 & 1.27 & High \\
\hline 45 right & 4.47 & 0.52 & 3.47 & 0.52 & 1.00 & 5.00 & 0.58 & 1.92 & High \\
\hline Middle & 4.60 & 0.51 & 3.60 & 0.51 & 1.00 & 5.26 & 0.61 & 1.96 & High \\
\hline 45 lift & 4.27 & 0.70 & 3.60 & 0.51 & 0.67 & 2.91 & 0.32 & 0.96 & High \\
\hline $180 \mathrm{lift}$ & 4.60 & 0.51 & 3.53 & 0.52 & 1.07 & 5.63 & 0.64 & 2.10 & High \\
\hline
\end{tabular}

(T) Table value on $\mathrm{P} \leq 0.05=1.76$

Effect Size: Low $=0.2-$ Moderate $=0.5-$ High $=0.8$

Table (4) indicated statistically significant differences on $\mathrm{P} \leq 0.05$ and a high effect size according to Cohen's equation between the post-measurements of the preferred and non-preferred arm on all technical tests as (t) calculated values were from (2.91) to (5.63) which were higher than its table value (1.76) while the effect size ranged from (0.96) to (2.10) in favor of the preferred arm.

\section{Discussion}

Table (2) indicated the positive effects of the recommended educational program for breaching learning plateau on improving the three-point shot with the preferred arm. This is consistent with Arias et al 2011, Arias et al (2012), Tsai et al (2006) , Garzon (2011), Pojskic et al (2011), Rojas et al 2000, Southerland et al (1989) and Widdon \& Reynolds 1983 who indicated that all coaches agreed on the importance of shooting as one of the basketball basics and without it the team can never achieving victory. Shooting is affected by the player's behavior before shooting and his/her experiences in some situations. This behavior is more predicative about shooting success than the number of trials. There is a close relation among shooting accuracy, distance and player's position. Intensive training programs are highly effective for basketball players as they aim to improve their 
performance. In addition, using training aids and studying the motor performance of the shot have positive effects on calibrating the program. This is consistent with the positive effects of the educational program for breaching the learning plateau on the basis of improving the technical performance level as it contributed in improving the shot. Players became aware of the timing, distance and position of shooting. This improved their attitudes towards shooting. The program also concentrated on the player's individual skills and correcting mistakes through feedback after each shot and enforcing the correct performance. This proves the first hypothesis.

Table (3) indicated the positive effects of the recommended program for breaching learning plateau on improving the three-point shot with the non-preferred arm. This is in agreement with Schiffer (2011) and Jasem (2008) who indicated the importance of breaching the learning plateau to improve the players' performance level and to avoid its fixity to a certain level. This should be done through using new exercises and training aids with the non-dominant part of the body (the non-preferred arm) as this fixity hinder players from reaching higher levels. The new exercises and training aids used in the educational program had positive effects on learning the three-point shot. Jasem(2008)indicated that motor learning is a positive change in performance through various methods like changing the preferred part of the body for this skill and finding solutions for motor problems and all this helps breaching the learning plateau. This proves the second hypothesis.

Table (4) indicated the positive effects of the recommended program for breaching learning plateau on improving the three-point shot from all possible angles comparing the preferred arm to the non-preferred arm. Results indicated that the program improved the successful performance of shooting through situational/competitive exercises with progressive performance and continuous correction for errors. Shooting is the main aim in basketball as the game is won by scoring the highest possible points. This makes shooting the most influential factor affecting game results. Although basic skills are of major importance in basketball, shooting comes on top of them all as it is the resultant effect of the effective performance of all skills gathered together.

Athletic training represents the specific physical and educational process based on physical exercises and aims to improve all the athlete's qualities required for the highest possible level of a specific sports activity. Planning is of major importance for training to achieve the best possible level (Abd El-Fattah 2012).

Achieving elite levels is not possible with mere coincidence. It can only be achieved, especially for junior athletes, through regular long-term training according to sound scientific principles (Abd El-Khalek 2005).

This is consistent with Arias et al (2011), Arias et al (2012), Jasem (2008) and Tsai et al 2006 who indicated positive effects for experimental programs on improving shooting skills of basketball player. To improve shooting, it is necessary to improve the performance level of technical exercises through exposing players to progressive requirements of difficulty. This is also consistent with Fawzy (2013), Abu Al-Ela (2012), Abd ElKhalek (2005) and Ibrahim (2002) in that researchers of motor learning think that the performance level of players can be improved any time and there is a close relation between time, errors and amount of performance on condition that suitable methods are used.

This is also consistent with Yamashita et al (2015) who indicated a physiological maximum limit for junior athletes where their learning becomes more difficult and even stops. If the athlete reaches this limit, the coach should find a way to breach this plateau. Schiffer (2011) indicated the importance of breaching the learning plateau through using training aids. Jasem (2008) also indicated that performance can be improved through training the non-preferred arm of basketball players via training aids as this may lead to positive improvements of performing the free throw.

Rojas et al (2000) and Whiddon \& Reynolds (1983) agreed that coaches consider shooting as one of the most important basic skills and the main and only way to score points in basketball.

There are differences between learning plateaus and slight vibrations on the learning curves as these vibrations may represent optimum decrease and increase happening between training stages. This phenomenon is common on most learning curves. Coaches should monitor their athletes to identify the real reasons behind their learning plateaus with special consideration for the learner's morals, especially during critical moments. In this case encouragement and compliments may play a vital role in generating successful experiences Ibrahim (2002). The researcher thinks that these clear differences between the preferred and non-preferred arms are due to the 
recommended program for the non-preferred arm as the program forced the players to train with this particular arm. Training was initiated with an arm not acquainted to be used in shooting. Junior athletes repeated performance under changing situations and all mistakes were corrected. This means that the learning plateau was breached and this improved the performance of the preferred arm. This proves the third hypothesis.

\section{Conclusions}

- There are statistically significant differences on $\mathrm{P} \leq 0.05$ with effect size between (5.55) and (7.24) between the pre- and post-measurements of the technical test for the preferred arm in favor of the post-measurements.

- There are statistically significant differences on $\mathrm{P} \leq 0.05$ with effect size between (4.12) and (5.88) between the pre- and post-measurements of the technical test for the non-preferred arm in favor of the post-measurements.

- There are statistically significant differences on $\mathrm{P} \leq 0.05$ with effect size between (0.96) and (2.10) between the post-measurements of the technical test for the preferred and non-preferred arms in favor of the preferred arm.

- The recommended program for breaching the learning plateau had positive effects on the performance level of the three-point shot with the preferred arm.

\section{Recommendations}

- Coaches should train their players with the non-preferred arm inside the regular training program units to breach learning plateau for the three-point shot.

- Exercises for the non-preferred arm should be progressive in speed with immediate correction of learners' mistakes.

- Exercises and training aids should be varied for breaching the learning plateau.

\section{References}

1- Abd El-Fattah, Abu Al-Ela A. (2012): Contemporary Sports Training (physiological principles - junior training - training plans - long-term training - training load errors). Dar Al-Fikr Al-Araby, Cairo - Egypt, PP: 57, 168170 (in Arabic)

2- Abd El-Khalek, Isam El-Din (2005): Sports Training (theories and practices). Munshaat Al-Maaref Alexandria - Egypt, P: 62 (in Arabic)
3- Arias, J. L., Argudo Iturriaga, F. M., \& Alonso, J. I. (2011). Effect of two different forms of three-point line on game actions on girls' mini-basketball. South African Journal for Research in Sport, Physical Education and Recreation.

4- Arias, J., Argudo, F., \& Alonso, J. (2012). Effect of basketball mass on shot performance among 9-11 year-old male players. International Journal of sports science and coaching, 7(1), 69-80.

5- Fawzy, Ahmed A. (2013): Learning Psychology for Sports Motor skills. Dar Al-Wafaa Press - Alexandria Egypt, P: 23 (in Arabic)

6- Garzón, E. B., Lapresa, A. D., Anguera, A. M., \& Arana, I. J. (2011). Observational analysis of the free throw shot made by grassroots basketball players.

Psicothema, 23(4), 851-857.

7- Ibrahim, Marwan A. (2002): Physical Growth and motor learning. International Scientific House for Printing and Distribution - Amman - Jordan, PP: 119-120 (in Arabic)

8- Jasem, Mazen H. (2008): Effects of using training aid on improving the accuracy of free throw in basketball. Scientific Journal of Physical Education, Vol.1, No.7 Babel University - Iraq (in Arabic)

9- KURZ, T. (2001). Science of sports training: How to plan and control training for peak performance. Island Pond, VT: Stadion Publishing Company

10- Miller, S., \& Bartlett, R. (1996). The relationship between basketball shooting kinematics, distance and playing position. Journal of sports sciences, 14(3), 243253.

11- Pojskić, H., Šeparović, V., \& Užičanin, E. (2011).Reliability and factorial validity of basketball shooting accuracy tests. Sport Scientific and Practical Aspects, 8, 25-32.

12- Rojas, F. J., Cepero, M., Oña, A., \& Gutierrez, M. (2000). Kinematic adjustments in the basketball jump shot against an opponent. Ergonomics, 43(10), 1651-1660.

13- Schiffer, J. (2011) Training to overcome the Speed Plateau, IAAF, 26:1/2; 7-16

14- Southard, D., Miracle, A., \& Landwer, G. (1989). Ritual and free- throw shooting in basketball. Journal of sports sciences, 7(2), 163-173. 
15- TABACHNIK, B. (1992). The speed chute. NSCA Journal,14(4), pp. 75-80

16- Tsai, C., Ho, W., Lii, Y., \& Huang, C. (2006). The kinematic analysis of basketball three point shoot after high intensity program. In XXIV Isbs Symposium .pp. 276-279.
17- Whiddon, N. S., \& Reynolds, H. (1983). Teaching basketball. Burgess Publishing Company.

18- Yamashita, M., Kawato, M., \& Imamizu, H. (2015). Predicting learning plateau of working memory from whole-brain intrinsic network connectivity patterns. Scientific reports, 5.Article number, 7622 . 